\section{Paternal dapoxetine is detrimental to reproductive outcomes}

Dapoxetine, a selective serotonin reuptake inhibitor specifically developed for the treatment of premature ejaculation, has a negative effect on male-mediated reproductive outcomes in rats, according to data published in the International Journal of Impotence Research.

Healthy male rats were assigned to receive dapoxetine at doses of $2 \mathrm{mg} / \mathrm{kg}$, $4 \mathrm{mg} / \mathrm{kg}$, or $8 \mathrm{mg} / \mathrm{kg}$ daily and sperm parameters, sexual behaviour and reproductive outcomes were assessed.

Levels of follicle-stimulating hormone, luteinizing hormone and testosterone were significantly decreased in rats receiving $4 \mathrm{mg} / \mathrm{kg}$ or $8 \mathrm{mg} / \mathrm{kg}$ dapoxetine. Dapoxetine had a dose-dependent adverse effect on spermatid and spermatozoa counts, and an increase in the number of dead spermatozoa was observed. Rats receiving the two highest doses exhibited a significant reduction in normally formed sperm, attributed to teratospermia. Sperm motility was also significantly inhibited and the number of viable sperm and the integrity of sperm DNA of rats that received $4 \mathrm{mg} / \mathrm{kg}$ or $8 \mathrm{mg} / \mathrm{kg}$ was decreased.

With regards to sexual behaviour, only $8 \mathrm{mg} / \mathrm{kg}$ dapoxetine negatively affected the copulation index but both $4 \mathrm{mg} / \mathrm{kg}$ or $8 \mathrm{mg} / \mathrm{kg}$ dapoxetine reduced precopulatory behaviour and rats receiving these doses took longer to impregnate female rats. The libido index was also significantly reduced in these rats.

Fecundity was significantly decreased in rats that were given the two higher doses, with increased instances of preimplantation and postimplantation loss of embryos in untreated females and smaller fetal sizes. Significantly increased numbers of early and late resorptions and reduced implantation sites and live fetuses resulted from the copulation of rats that received $8 \mathrm{mg} / \mathrm{kg}$ dapoxetine.

These findings indicate that chronic dapoxetine exposure can have an adverse

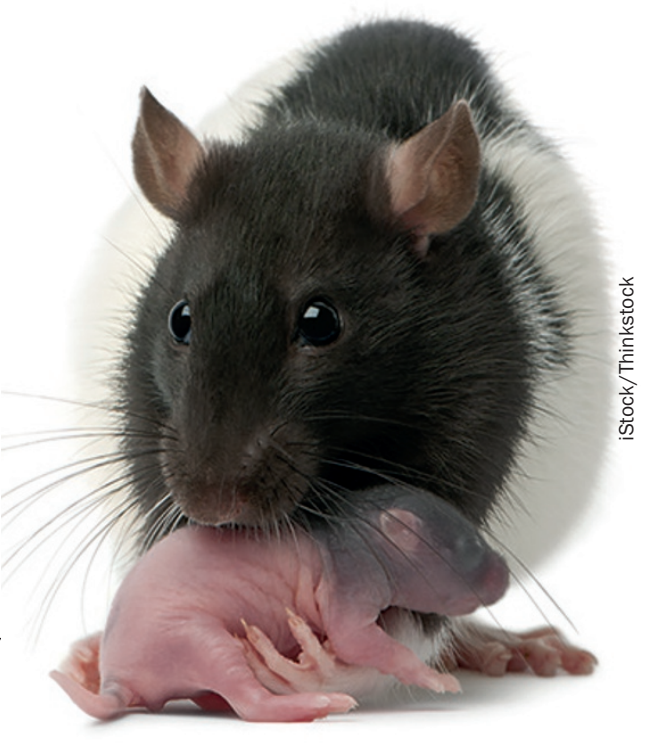

effect on fertility parameters, sexual behaviour, and reproductive outcomes in male rats. These data should be considered when prescribing dapoxetine to men with premature ejaculation.

Louise Stone

Original article EIMazoudy, R. et al. Paternal dapoxetine administration induced deterioration in reproductive performance, fetal outcome, sexual behavior and biochemistry of male rats. Int. J. Impot. Res. doi:10.1083/ ijir.2015.16 